\title{
ОПРЕДЕЛЕНИЕ НАИБОЛЕЕ ЭФФЕКТИВНЫХ ИННОВАЦИЙ В СФЕРЕ ЖИЛИЩНОГО СТРОИТЕЛЬСТВА
}

\begin{abstract}
АНнотАцИЯ. В статье рассмотрены инновации в сфере жилищного строительства, приведена классификация данного вида инноваций. Показаны основные направления инноваций в жилищном строительстве: системы бережливого строительства и информационного моделирования как основы снижения издержек (по оценкам экспертов порядка 20 \% организационных затрат); повышение качества строительства на основе радикальных инноваций в производстве строительных материалов (энергосберегающие, экологичные материалы, 3D-панели и т.п.); энергосберегающие фасады, представляющие двухслойные сэндвич-панели, разработанные и производимые компанией ООО ПКФ «Термодом»; крышные котельные, устанавливаемые на крышах многоэтажных жилых домов, что позволило уйти от прокладки подземных теплотрасс и потери тепла при транспортировке теплоносителя и другие. Рассмотрены наиболее значимые барьеры на пути расширения области применения инноваций в жилищном строительстве. На основе характеристики технологической и экономической эффективности инновационных технологий выделены преимущества внедрения инноваций в жилищном строительстве, обеспечивающие быстрый рост жилищного строительства. В заключении сформулированы направления развития бизнес-регулирования инноваций в сфере жилищного строительства.
\end{abstract}

кЛЮчЕВЫЕ словА. Регулирование бизнеса; застройщик; инвестиционная деятельность; инновации; инновационные технологии; теплозащита; энергоэффективность.

ИНФОРМАЦИЯ О СТАТЬЕ. Дата поступления 15 сентября 2017 г.; дата принятия к печати 19 декабря 2017 г.; дата онлайн-размещения 29 декабря 2017 г.

E. V. Batoyeva

Baikal State University, Irkutsk, Russian Federation

\section{DETERMINATION OF THE MOST EFFECTIVE INNOVATIONS IN THE FIELD OF HOUSING CONSTRUCTION}

\begin{abstract}
The article considers innovations in the sphere of housing construction, and gives classification of this type of innovation. It shows the main directions of innovations in housing construction: the systems of lean construction and information modeling as a basis for reduction of costs (according to experts, about $20 \%$ of organizational costs); improvement of the quality of construction on the basis of radical innovations in the production of building materials (energy-saving, ecological materials, 3D panels, etc.); energy-saving facades, representing two-layer sandwich panels, developed and manufactured by OOO PCF «Thermodom»; roof boiler houses installed on the roofs of high-rise apartment houses, which allows to escape from the laying of underground heating mains and heat loss during transportation of the coolant, and others. The most significant barriers on the way of expanding the innovations' application in the housing construction are considered. The advantages of introducing innovations in the housing construction, which ensure a rapid growth of the housing construction, are highlighted, based on characteristics of technological and economic efficiency of innovative technologies.

KEYWORDS. Business regulation; developer; investment; innovation; innovative technology; thermal protection; energy efficiency.
\end{abstract}

(C) Э. В. Батоева, 2017

\section{Baikal Research Journal}


ARTICLE INFO. Received September 15, 2017; accepted December 19, 2017; available online December 29, 2017.

Актуальность темы статьи обусловлена тем, что повышение требований к качеству, энергоэффективности, экологичности, безопасности в сфере жилищного строительства обусловливает дальнейший рост себестоимости строительного производства и строительного бизнеса в целом, в связи с необходимостью дополнительных издержек на внедрения новых технологий, материалов, исполнения новых требований. Как следствие, рост рыночной стоимости жилья. В то же время наблюдается снижение покупательской способности в условиях кризиса. При таких условиях снижается экономическая эффективность строительного бизнеса, его привлекательность для инвесторов, предпринимательства. Как следствие, снижается объем строительства, его продукции. Что, в конечном итоге отрицательно влияет на уровень доступности жилья. При этом сфера жилищного строительства традиционно несет особую социально-экономическую нагрузку и обеспеченность жильем, уровень капитальных вложений в строительства, а также соответствующий уровень и качество жизни населения всегда включаются в региональные оценки социально-экономического положения, прогнозные расчеты и разрабатываемые стратегии развития территории.

Особенно остро эти факторы влияют в Сибирском регионе в связи с особенностями строительного производства в условиях климата Сибири: требования к жилью по многим техническим параметрам выше, сезонность строительства, более высокая себестоимость строительства в зимних условиях. Строительство осложняется и особенностями строения грунта и т.д. (например, талики, солифлюкция, бугры пучения, морозобойные трещины, термокаст). Кроме того, в ряде районов Сибирского региона требуется применения дорогостоящей спецтехники для проведения жилищного строительства.

Немаловажным фактором является и рост требований населения к качеству возводимого жилья, что решается с помощью внедрения научно-технических инноваций в технологии жилищного строительства и применяемые материалы.

Инновация - внедрённое или внедряемое новшество, способствующее качественному росту результативности процессов или продукции, востребованных на рынке [1]. Инновации в целом и в строительной отрасли в частности делятся на два основных типа: радикальные и усовершенствующие. В силу специфики жилищного строительства, основанного на достаточно жестких требованиях различных СНИП и СТО (для Сибирского региона наиболее важными являются СП 50.13330.2012 «Тепловая защита зданий. Актуализированная редакция СНиП 23-02-2003» и СТО 00044807-001-2006 «Теплозащитные свойства ограждающих конструкций зданий»), основная масса инноваций в данной сфере является усовершенствующими.

Представим в табл. 1 предлагаемую классификацию инноваций в сфере жилищного строительства.

\section{Классификация инноваций классификацию инноваций}

Таблица 1 в сфере жилищного строительства [2]

\begin{tabular}{|l|l|}
\hline \multicolumn{1}{|c|}{ Признак классификации } & \multicolumn{1}{c|}{ Виды нововведений } \\
\hline По степени новизны & Радикальные, усовершенствующие \\
\hline \multirow{2}{*}{ По характеру применения } & $\begin{array}{l}\text { Совершенствование объемно-планировочных решений } \\
\text { Совершенствование конструктивных факторов } \\
\text { Применение прогрессивных материалов }\end{array}$ \\
\hline
\end{tabular}

\section{Baikal Research Journal}

электронный научный журнал Байкальского государственного университета 
Окончание табл. 1

\begin{tabular}{|l|l|}
\hline \multicolumn{1}{|l|}{ Признак классификации } & \multicolumn{1}{|c|}{ Виды нововведений } \\
\hline По источнику & $\begin{array}{l}\text { Научно-технологические } \\
\text { В связи с изменениями СНИП и СТО }\end{array}$ \\
\hline $\begin{array}{l}\text { По роли в воспроизвод- } \\
\text { ственном процессе }\end{array}$ & Потребительские и инвестиционные \\
\hline По масштабу & Градостроительные и поэлементные \\
\hline $\begin{array}{l}\text { Направленность нововве- } \\
\text { дения }\end{array}$ & $\begin{array}{l}\text { Для производителя и потребителя; для общества в целом; для } \\
\text { рынка }\end{array}$ \\
\hline
\end{tabular}

Для увеличения объемов жилищного строительства экстенсивным путем требуется снижение себестоимости строительных работ и уменьшение сроков проведения работ. Данные два направления активно реализуются в современных инновациях, как в сфере технологий строительства, так и строительных материалов.

Основными здесь можно отметить:

- системы бережливого строительства и информационного моделирования как основы снижения издержек (по оценкам экспертов порядка 20 \% организационных затрат);

- повышение качества строительства на основе радикальных инноваций в производстве строительных материалов (энергосберегающие, экологичные материалы, 3D-панели и т.п.);

- энергосберегающие фасады, представляющие двухслойные сэндвич-панели, разработанные и производимые компанией ООО ПКФ «Термодом»;

- крышные котельные, устанавливаемые на крышах многоэтажных жилых домов, что позволило уйти от прокладки подземных теплотрасс и потери тепла при транспортировке теплоносителя и т.д. [3].

Особенностью инноваций в сфере жилищного строительства является наличие комплексных инновационных систем строительства, одним из ярких примеров которых является технология с применением свай и колонн из трубобетона, внедряемая АО ММсковский ИМЭТ». Данная технология позволяет почти полностью устранить затраты на проведение земляных работ, увеличить уровень теплозащиты, позволяет вести строительные работы в том числе в условиях холодов и т.д.

Несмотря на широкий перечень отечественных и зарубежных инновационных разработок в области жилищного строительства их внедрение составляет не более $0,5 \%$ инвестиций в отрасль.

В.В. Выгулярный выделяет такие факторы недостаточно высокого роста применения инноваций в жилищном строительстве как:

- нежелания применять инновации со стороны строительных компаний, так как внедрение новой технологии строительства неизбежно ведет к изменениям производственной и функциональной структуры самой строительной компании;

- научно-техологические инновации требуют найма более квалифицированных и более оплачиваемых специалистов, либо значительных затрат на повышение квалификации имеющегося персонала;

- внедрение одних инноваций зачастую приводит к последующему совершенствованию также и других технологий в строительной компании, что может повлечь дополнительные денежные и временные затраты [4; 5].

E. B. Черепанова дополнительно указывает на такие факторы как:

- отсутствие зачастую соответствующей нормативно-технической документации на инновационные материалы и/или технологии строительства, что приводит к негативным итогам экспертизы строительных объектов и убыткам для строительной компании;

\section{Baikal Research Journal}


- применение инновационных технологий и материалов требует модификации типовых проектов или же полной замены, что влечет значительные затраты труда и средств;

- на большинстве предприятий строительной сферы отсутствуют специалисты по инновационному менеджменту, которые могли бы показать и доказать эффективность для застройщика перехода на инновационные материалы и/или технологии даже с учетом всех вышеуказанных дополнительных издержек [6].

Также барьерами на пути внедрения инноваций в сфере жилищного строительства могут быть:

- циклический характер строительства;

- низкий уровень интеграции в отрасли, чрезмерная зависимость от субподрядчиков;

- многообразие строительных стандартов и нормативов;

- обилие региональных особенностей как в техническом, так и в правовом аспектах;

- отсутствие унифицированной системы апробации и сертификации новых продуктов и др. [6].

Для увеличения уровня инвестиций в инновации в сфере жилищного строительства необходимо формирование программы бизнес-регулирования данной отрасли экономики, т.е. системы совместного государственного и частного управления с наличием целей, функций, инструментов и методов регулирования. Необходимость такой системы обусловлена отсутствием у девелоперов экономической заинтересованности в росте жилищного строительства, так как это неизбежно снизит уровень среднерыночных цен, а ведь строить меньше жилья по более высоким ценам, конечно же, выгоднее.

В тоже время возможность широкого применения государственного воздействия на сферу именно жилищного строительства обусловлено тем, что практически каждая третья квартира сдается по условиям ипотечных программ, поддерживаемых правительством РФ. Включение вопросов регулирования инноваций в программу поддержки ипотечного кредитования является действенным рычагом воздействия на девелоперов, наряду с корректировками СНИП и СТО.

Таким образом, основным проблемным моментом становится реализация частно-государственного партнерства в рассматриваемой сфере в рамках специальной программы по инвестированию в инженерную, транспортную и социальную инфраструктуру для жилищного строительства [7]. Например, в Японии действует «официально закрепленное в национальном законодательстве требование к шести крупнейшим национальным строительным корпорациям инвестировать не менее $0,5 \%$ своего годового оборота в НИОКР» [6].

Как полагает Л.А. Солдатова, «программа бизнес-регулирования сферы жилищного строительства на региональном уровне, должна содержать не менее пяти этапов, включая:

- формирование команды профессионалов и разработку управленческих решений;

- получение необходимой информации о ситуации в регионе, структурно-морфологический анализ ситуации, определение необходимых ресурсов;

- разработку графика реализации мероприятий;

- оценку и анализ результативности выполнения бизнес- регулирования по показателям жилищной отрасти в следующей периоде;

- выработку комплекса рекомендаций по прогнозированию состояния сферы жилищного строительства в перспективе» [8].

\section{Baikal Research Journal}


Целесообразно и изменение системы строительного нормирования по опыту западных стран (Великобритания, Норвегия, Швеция и т.д.) в сторону применения потребительских характеристик по строительной продукции, а не «детализированых предписаний к технологиям и применяемым материалам» [9].

Как было указано выше, применение отдельных инновационных технологий строительства или же переход на инновационные материалы требуют соответствующей корректировки организационной и функциональной структуры строительной компании, модернизации информационного обеспечения и т.д. То есть внедрение отдельных инноваций требуют таких же вложений ресурсов, как и применение комплексных решений в связи со спецификой организации деятельности строительных организаций. Поэтому наиболее эффективным представляется переход именно на полную модернизацию компании под применение инновационных технологий строительства на основе новых материалов. В качестве примера проведем расчет эффективности инвестиций с точки зрения сроков и стоимости строительства в рамках проекта типового 9-этажного здания.

Для инвестора внедрение инноваций в области жилищного строительства должно привести к таким результатам как:

1. Снижение отрицательного денежного потока - инвестиционной стоимости проекта строительства (реконструкции);

2. Рост положительного денежного потока от эксплуатации объекта недвижимости;

3. Сокращение длительности инвестиционно-строительного цикла, обеспечивающее рост экономической эффективности капитала инвестора [10].

В своей статье М. Я. Бикбау приводит следующие усредненные технико-экономические показатели жилых домов различных архитектурно-строительных систем на 1 м² $^{2}$ (для 9 этажных зданий).

Таблица 2

Усредненные технико-экономические показатели жилых домов различных архитектурно-строчтельных систем на $1 \mathrm{~m}^{2}$ [11]

\begin{tabular}{|c|c|c|c|c|c|}
\hline Показатели & Ед. изм. & Монолит & $\begin{array}{c}\text { Кирпичный } \\
\text { дом }\end{array}$ & $\begin{array}{l}\text { Система } \\
\text { АРКОС }\end{array}$ & Система ИМЭТ \\
\hline $\begin{array}{l}\text { Расход железобетона на } \\
\text { несущий остов }\end{array}$ & $\mathbf{M}^{3}$ & 0,25 & 0,14 & 0,18 & 0,12 \\
\hline В т.ч. монолитного & $\mathbf{M}^{3}$ & 0,22 & 0,02 & 0,06 & - \\
\hline $\begin{array}{l}\text { Расход металла на несу- } \\
\text { щие конструкции }\end{array}$ & $\kappa \Gamma$ & 27,7 & 12,0 & 14,8 & 12,2 \\
\hline $\begin{array}{l}\text { Расход арматуры на пе- } \\
\text { рекрытия }\end{array}$ & $\kappa \Gamma$ & 28,5 & 8,4 & 14,6 & 9,6 \\
\hline $\begin{array}{l}\text { Расход материалов на } \\
\text { наружные стены }\end{array}$ & $\mathbf{M}^{3}$ & 0,3 & 0,8 & 0,3 & 0,25 \\
\hline Масса наружной стены & $\kappa \Gamma$ & 650 & 500 & 250 & 220 \\
\hline Удельная масса здания & $\mathrm{T}$ & 1,7 & 2,4 & 1,0 & 0,8 \\
\hline $\begin{array}{l}\text { Обеспечение свободных } \\
\text { планировочных решений }\end{array}$ & - & $\begin{array}{l}\text { Без огра- } \\
\text { ничений }\end{array}$ & $\begin{array}{c}\text { Не обеспе- } \\
\text { чивается }\end{array}$ & $\begin{array}{c}\text { Без ограни- } \\
\text { чений }\end{array}$ & $\begin{array}{c}\text { Без ограниче- } \\
\text { ний }\end{array}$ \\
\hline Сетка колонн & M & - & - & \begin{tabular}{|l|} 
Любая до \\
$7,2 \times 7,2$ \\
\end{tabular} & $\begin{array}{c}\text { Любая до } \\
8,0 \times 8,0\end{array}$ \\
\hline $\begin{array}{l}\text { Стоимость возведения } \\
\text { коробки здания }\end{array}$ & $\%$ & 130 & 130 & 90 & 75 \\
\hline Сроки строительства & Эт/мес. & 3,5 & $2-2,5$ & 4 & 7 \\
\hline
\end{tabular}

Реализация новой архитектурно-строительной системы ИМЭТ предусматривает сочетание быстровозводимых каркасов из трубобетона и преднапряженными

\section{Baikal Research Journal}


перекрытиями с применением новых ограждающих конструкций в виде навесных панелей, что позволит снизить массу высотных и многоэтажных зданий в $2-2,5$ раза, радикально сократит расходы бетона и металла, значительно уменьшит сроки и себестоимость строительства [11].

Рассмотрим экономическое обоснование строительства многоэтажного дома (9этажей, один подъезд, 36 квартир площадью $42 \mathrm{~m}^{2}, 58 \mathrm{~m}^{2}, 64 \mathrm{~m}^{2}, 90 \mathrm{~m}^{2}$ ).

Сметная стоимость строительства здания по монолитной технологии:

1. Стоимость общестроительных работ 8144990 p.

2. Стоимость материалов $191770 \mathrm{p}$.

3. Накладные расходы составят $957010 \mathrm{p}$.

4. Сметная прибыль составит 613440 р.

Общая сумма затрат составит $10026820 \mathrm{p}$.

Условная сметная стоимость строительства здания по технологии ИМЭТ:

1. Стоимость общестроительных работ $7406710 \mathrm{p}$.

2. Стоимость материалов $191770 \mathrm{p}$.

3. Накладные расходы составят $855770 \mathrm{p}$.

4. Сметная прибыль составит $55080 \mathrm{p}$.

Общая сумма затрат составит $9094660 \mathrm{p}$.

При одноэтапных капитальных вложениях и постоянных эксплуатационных расходах совокупный экономический эффект определяется разностью полных приведенных затрат с добавлением эффекта от ускорения строительства.

С учетом НДС и индексации сумма приведенных затрат по смете № 1 составит: $10026820 \cdot 1,18 \cdot 5,35=63299314,66 \mathrm{p}$.

Среднегодовая стоимость производственных основных фондов и оборотных средств, участвующих в сфере строительства составит:

Капитальные затраты в основные фонды рассчитываются по формуле:

$$
\kappa_{\text {о.ф. }}=\kappa_{\text {об }}+\kappa_{\text {мон }}+\kappa_{\text {пр }}+\kappa_{\text {тр.заг }}+\kappa_{\text {подг }} \text {, }
$$

где $\kappa_{\text {об̆}}-$ стоимость оборудования, млн $\mathrm{p} ., \kappa_{\text {мон }}-$ стоимость монтажа, млн $\mathrm{p}$, $\mathrm{K}_{\text {пр }}$ - стоимость проектных работ, млн р., $\kappa_{\text {тр.заг }}-$ стоимость транспортно-заготовительных работ, млн р., $\kappa_{\text {подг. }}$ - стоимость подготовительных работ, млн $\mathrm{p}$.

$$
\text { Коб = } 23810 \text { тыс. р. }
$$

Стоимость монтажа оборудования и пуско-наладочных работ принимается ориентировочно на уровне $25 \%$ от стоимости основного технологического оборудования.

$$
\mathrm{K}_{\text {мон }}=0,25 \cdot \mathrm{K}_{\text {об, }}
$$

$\kappa_{\text {мон }}=0,25 \cdot 23810=5952,5 ; \kappa_{\text {мон }}=5952,5$ тыс. $\mathrm{p}$.

Стоимость проектных работ принимается ориентировочно на уровне $2,5 \%$ от стоимости основного технологического оборудования.

$$
\mathrm{K}_{\text {пр }}=0,025 \cdot\left(\mathrm{K}_{\text {об }}+\mathrm{K}_{\text {мон }}\right) \text {, }
$$

$\kappa_{\text {пр }}=0,025 \cdot(23810+5952,5)=744 ; \kappa_{\text {пр }}=744$ тыс. р.

Стоимость транспортно-заготовительных работ принимается ориентировочно на уровне 1,5 \% от стоимости основного технологического оборудования

$$
\begin{gathered}
\mathrm{K}_{\text {тр.заг }}=0,015 \times \kappa_{\text {об, }} \\
\mathrm{K}_{\text {тр.заг }}=0,015 \cdot 23810=351,75 ; \mathrm{K}_{\text {тр.заг }}=351,75 \text { тыс. } \mathrm{p} .
\end{gathered}
$$

\section{Baikal Research Journal}


Стоимость подготовительных работ принимается ориентировочно на уровне $4 \%$ от стоимости основного технологического оборудования.

$$
\mathrm{K}_{\text {подг }}=0,04 \cdot \mathrm{K}_{\text {об, }}
$$

$\mathrm{K}_{\text {подг }}=0,04 \cdot 23810=952,4 ; \mathrm{K}_{\text {подг }}=952,4$ тыс. $\mathrm{p}$.

Капитальные затраты в основные фонды равны:

$\mathrm{K}_{\text {о.ф. }}=23810+5952,5+744+351,75+952,4=31810,65 ; \kappa_{\text {о.ф. }}=31810,65$ тыс. р.

Сметная стоимость объекта сопряженных капитальных вложений в производство строительных конструкций и материалов составит $191770 \cdot 1,18 \cdot 5,35=12$ 10,64 тыс. р.

Эксплуатационные затраты, включающие стоимость капитального ремонта и расходы по текущему ремонту и содержанию составят $10 \%$ от сметной стоимости или $63299314,66 \cdot 0,1=6329,93$ тыс. р.

Расчетный период эксплуатации объекта составляет 1,5 года.

Полные приведенные затраты в соответствии с Инструкцией СН 423-71 без учета разновременности по варианту 1 составят:

$63299,31+31810,65+1210,64+6329,93 \cdot 1,5=105815,495$ тыс. р.

С учетом НДС и индексации сумма приведенных затрат по смете № 2 составит: $9094660 \cdot 1,18 \cdot 5,35=57414588,58$ р. или 57414,59 тыс. p.

Среднегодовая стоимость производственных основных фондов и оборотных средств, участвующих в сфере строительства составит:

Коб $=25000$ тыс. $\mathrm{p}$.

Стоимость монтажа оборудования и пуско-наладочных работ:

$\mathrm{K}_{\text {мон }}=0,25 \cdot 25000=6250 ; \mathrm{K}_{\text {мон }}=6250$ тыс. $\mathrm{p}$.

Стоимость проектных работ:

$\kappa_{\text {пр }}=0,025 \cdot(25000+6250)=781,25 ; \kappa_{\text {пр }}=781,25$ тыс. .

Стоимость транспортно-заготовительных работ:

$\mathrm{K}_{\text {тр.заг }}=0,015 \cdot 25000=375 ; K_{\text {тр.заг }}=375$ тыс. .

Стоимость подготовительных работ:

$\kappa_{\text {подг }}=0,04 \cdot 25000=100 ; \kappa_{\text {подг }}=1000$ тыс. $\mathrm{p}$.

Капитальные затраты в основные фонды равны:

$\kappa_{\text {о.ф. }}=25000+6250+781,25+375+1000=33406,25 ; \kappa_{\text {о.ф. }}=33406,25$ тыс. р.

Сметная стоимость объекта сопряженных капитальных вложений в производство строительных конструкций и материалов составит $191770 \cdot 1,18 \cdot 5,35=1210,64$ тыс. р.

Эксплуатационные затраты, включающие стоимость капитального ремонта и расходы по текущему ремонту и содержанию составят $10 \%$ от сметной стоимости или $57414,59 \cdot 0,1=5741,46$ тыс. р.

Расчетный период эксплуатации объекта составляет 6 месяцев.

Полные приведенные затраты в соответствии с Инструкцией СН 423-71 без учета разновременности по варианту 2 составят:

$57414,59+33406,25+1210,64+5741,46 \cdot 0,6=95476,36$ тыс. p.

Суммарный эффект от различных форм проявления фактора времени при сокращении продолжительности строительства при применении ИМЭТ составит $15 \%$ о суммы или $95476,36 \cdot 0,15=14321,45$ тыс. р.

Совокупный эффект в общем виде составит:

$\ni_{\text {сов }}=102650,53-95476,36+14321,45=21495,62$ тыс. р.

Произведем расчет показателей доходности и окупаемости инвестиций.

Выручка по проекту составит 81891,79 тыс. р. Предположим поступление платежей по проекту в течение 2018 гг.

Затраты по проекту составят 57 414,59 тыс. р.

Ставка дисконтирования составит $35,3 \%$.

\section{Baikal Research Journal}


Представим в табл. 3 рассчитанные показатели эффективности.

Таблица 3

Сводная таблица показателей эффективности

\begin{tabular}{|l|c|c|c|}
\hline \multicolumn{1}{|c|}{ Показатель } & Обозначение & Расчетное значение & Значение \\
\hline Чистый дисконтированный доход, тыс. p. & ЧDD & 228,35 & $>0$ \\
\hline Чистая текущая стоимость, тыс. р. & ЧТС & 228,35 & $>0$ \\
\hline Индекс доходности, тыс. р./ тыс. p. & ИD & 1,054 & $>1$ \\
\hline Рентабельность проекта, \% & Rпр & 1,8 & $>0$ \\
\hline Среднегодовая рентабельность, \% & Rср & 5,4 & $>0$ \\
\hline Срок окупаемости, месс. & Ток. & 16 & $<\mathrm{Tp}=7$ лет \\
\hline Внутренняя норма, доходности, \% & ВНД & 30 & $>\mathrm{d}=0,6$ \\
\hline
\end{tabular}

Исходя из анализа экономических показателей, можно сделать вывод, что предлагаемый проект строительства многоэтажного дома по технологии ИМЭТ целесообразен для реализации, экономически привлекателен и выгоден в связи с более низкими значениями приведенной стоимости строительства и получением от реализации проекта дохода.

Таким образом, в настоящее время в строительной отрасли разработаны и успешно применяются эффективные технологии возведения жилых зданий с высокими показателями теплозащиты. Стимулирование применения инновационных технологий в жилищном строительстве на государственном уровне позволит снизить себестоимость строительства, повысить срок службы возводимых зданий, увеличить объемы строительства в том числе за счет более высокого потребительского спроса.

Наиболее активно инновации применяются в сфере малоэтажного жилищного строительства, причем уровень радикальных, а не усовершенствующих инноваций здесь выше в 3-4 раза, чем в сфере многоэтажного жилищного строительства. Значительно снижают сроки и стоимость строительных работ, делая более доступными для населения собственные жилые дома технологии строительства на основе СИП-панелей, каркасных перекрытий, несъемных опалубок, купольного строительства и т.д. Также именно в малоэтажном строительстве применяются и инновационные строительные материалы, например 3D панели.

Таким образом, наиболее эффективными инновациями в сфере жилищного строительства, несомненно, являются комплексные усовершенствованные технологии строительства с применением радикальных инноваций в строительных материалах. Это позволяет значительно снизить затраты на проведение строительных работ, снижает себестоимость применяемых материалов, ускоряет сроки сдачи возводимых зданий и т.д.

Так как активное использование разработок отечественных производителей поддержит развитие передовых технологий жилищного строительства, снизит затраты на проведение общестроительных работ, то требуется формирование актуальной программы бизнес-регулирования на уровне государства. Целесообразно создание в жилищном строительстве системного интегратора, ответственного за внедрение новых технологий (например, в торгово- промышленном сегменте строительства этим совместно занимаются подрядчик и архитектор).

На уровне регионального социально-экономического планирования и прогнозирования актуальна реализация таких направлений как:

- формирование деятельности государственных институтов развития для эффективной работы с российскими и иностранными инвесторами;

\section{Baikal Research Journal}

электронный научный журнал Байкальского государственного университета 
- трансформация современной региональной инвестиционной политики, на основе долгосрочного планирования развития территорий как базовое условие привлечения стратегических инвесторов;

- систематизация инновационных подходов в строительной отрасли на различных коммуникационных площадках;

- электронное взаимодействие застройщика и органов власти;

- банковское финансирование строительных проектов, а также распространения результатов успешной практики инвестирования в проекты строительства, реализуемые на территории субъектов Российской Федерации.

\section{Список использованной литературы}

1. Волкова А. В. Инновации в сфере строительства: проблемы апробации в регионах // Среднерусский вестник общественных наук. - 2015. - Т. 10, № 4. - С. 194-204.

2. ЖЖитенев Ю. А. Инновации - путь в будущее / Ю. А. ЖЖитенёв // Локомотив. 2010. - № 11. - C. 2-3.

3. Хмызов А. С. Исследование состояния и перспектив развития индустрии строительных материалов в регионах Приволжского федерального округа // Современные проблемы науки и образования. - 2015. - № 1-1. - С. 734.

4. Выгулярный В. В. К проблеме определения экономических механизмов и инструментов стимулирования управленческих инноваций в строительстве / В. В. Выгулярный // Новая наука: проблемы и перспективы. - 2015. - № 2 (2). - С. 125-127.

5. Выгулярный В. В. Подходы к классификации управленческих инноваций в строительстве / В. В. Выгулярный, Ю. А. Елбаев, С. В. Завидей // Глобальный научный потенциал. - 2015. - № 11 (56). - С. 54-57.

6. Черепанова Е. В. Инвестиционная привлекательность инноваций в строительстве: проблемы и пути решения / Е. В. Черепанова, А. А. Норкин // Вестник современной науки. - 2015. - Т. 1, № 10-1 (10). - С. 75-79.

7. Алексеев А. А. Механизм технологических инноваций в строительстве / А. А. Алексеев // Экономические науки. - 2015. - № 131. - С. 73-76.

8. Солдатова Л. А. Разработка программы бизнес-регулирования сферы жилищного строительства / Л. А. Солдатова // Жилищные стратегии. - 2015. - Т. 2, № 2. - С. 91-100.

9. Сайфутдинова Р. В. Значимые проблемы продвижения инноваций в строительстве // Новая наука: Стратегии и векторы развития. - 2016. - № 2-1 (64). - С. 146-151.

10. Коваленко Т. Л., Абакумов Р. Г. Проявление инноваций в инвестиционностроительной деятельности / Коваленко Т. Л., Абакумов Р. Г. / Инновационная экономика: перспективы развития и совершенствования. - 2016. - № 1 (11). — С. 126-130.

11. Бикбау М. Я. Архитектурно-строительная система ИМЭТ - новая технологическая основа домостроения / М. Я. Бикбау // Режим доступа: http://www.concrete-union.ru/ articles/index.php?ELEMENT_ID=7110 (дата обращения 20.02.2017).

\section{References}

1. Volkova A. V. Innovation in the Construction Industry: Problems of Approbation in the Regions. Srednerusskii vestnik obshchestvennykh nauk = Central Russian Journal of Social Sciences, 2015, vol. 10, no. 4, pp. 194-204. (In Russian).

2. Zhitenev $\mathrm{Yu}$. A. Innovation is the way to the Future. Lokomotiv = Locomotive, 2010, no. 11, pp. 2-3. (In Russian).

3. Khmyzov A. S., Khrustalev B. B., Popova I. V. Research on the Status and Prospects of the Building Materials Industry in the Volga Federal District. Sovremennye problemy nauki $i$ obrazovaniya $=$ Modern problems of science and education, 2015, no. 1-1, pp. 734. (In Russian).

4. Vygulyarnyi V. V. On the problem of determining economic mechanisms and tools for stimulating managerial innovations in construction. Novaya nauka: problemy $i$ perspektivy $=$ New Science: Problems and Prospects, 2015, no. 2 (2). pp. 125-127. (In Russian).

5. Vygulyarnyi V. V., Elbaev Yu. A., Zavidei S. V. Approaches to the Classification of Managerial Innovations in Construction. Global'nyi nauchnyi potentsial = Global Scientific Potential, 2015, no. 11 (56), pp. 54-57. (In Russian).

\section{Baikal Research Journal}


6. Cherepanova E. V., Norkin A. A. Investment attractiveness of innovations in construction: problems and solutions. Vestnik sovremennoi nauki = Bulletin of Modern Science, 2015, vol. 1, no. 10-1 (10), pp. 75-79. (In Russian).

7. Alekseev A. A. Mechanism of technological innovations in construction. Ekonomicheskie nauki $=$ Economic sciences, 2015, no. 131, pp. 73-76. (In Russian).

8. Soldatova L. A. Development of the Business Regulation Programm for the Housing Construction Sphere. Zhilishchnye strategii = Russian Journal of Housing Research, vol. 2, no. 2, pp. 91-100. (In Russian).

9. Saifutdinova R. V. Significant problems of promoting innovations in construction. Novaya nauka: ctrategii $i$ vektory razvitiya $=$ New Science: Strategies and Vectors of Development, 2016, no. 2-1 (64), pp. 146-151. (In Russian).

10. Kovalenko T. L., Abakumov R. G. Display of Innovations in Building Activity. Innovatsionnaya ekonomika: perspektivy razvitiya $i$ sovershenstvovaniya $=$ Innovative Economy: Prospects for Development and Improvement, 2016, no. 1 (11), pp. 126-130. (In Russian).

11. Bikbau M. Ya. Architectural and construction system IMET - a new technological basis for house building. Available at: http://www.concrete-union.ru/articles/index. php?ELEMENT_ID=7110. (In Russian).

\section{Информация об авторе}

Батоева Элеонора Валентиновна - кандидат экономических наук, доцент, кафедра экономики и управления инвестициями и недвижимостью, Байкальский государственный университет, 664003, г. Иркутск, ул. Ленина, 11, e-mail: eleonora_batoeva@mail.ru.

\section{Author}

Eleonora V. Batoyeva - PhD in Economics, Associate Professor, Chair of Economy and Investment Management and Real Estate, Baikal State University, 11 Lenin St., 664003, Irkutsk; e-mail: eleonora_batoeva@mail.ru.

\section{Для цитирования}

Батоева Э. В. Определение наиболее эффективных инноваций в сфере жилищного строительства / Э. В. Батоева // Baikal Research Journal. - 2017. — T. 8, № 4. — DOI : 10.17150/2411-6262.2017.8(4).25.

\section{For Citation}

Batoyeva E. V. Determination of the most effective innovations in the field of housing construction. Baikal Research Journal, 2017, vol. 8, no. 4. DOI: 10.17150/24116262.2017.8(4).25. (In Russian).

\section{Baikal Research Journal}

